\title{
The Italian Validation of the Level of Exposure-Dental Experiences Questionnaire
}

\author{
Cristiano Scandurra ${ }^{1, *(\mathbb{D}}$, Roberta Gasparro ${ }^{1}$, Pasquale Dolce ${ }^{2}\left(\mathbb{D}\right.$, Vincenzo Bochicchio ${ }^{3}$, \\ Benedetta Muzii ${ }^{4}{ }^{\circledR}$, Gianrico Spagnuolo ${ }^{1}{ }^{1}$, Gaetano Marenzi ${ }^{1}$, Gilberto Sammartino ${ }^{1}$ and \\ Nelson Mauro Maldonato ${ }^{1}$ \\ 1 University of Naples Federico II, Department of Neuroscience, Reproductive Sciences and Dentistry, \\ Naples 80131, Italy; roberta.gasparro88@gmail.com (R.G.); gspagnuo@unina.it (G.S.); \\ gaetano.marenzi@tiscali.it (G.M.); gilberto.sammartino@unina.it (G.S.); \\ nelsonmauro.maldonato@unina.it (N.M.M.) \\ 2 University of Naples Federico II, Department of Public Health, Naples 80131, Italy; pasquale.dolce@unina.it \\ 3 University of Calabria, Department of Humanistic Studies, Cosenza 87036, Italy; \\ vincenzo.bochicchio@unical.it \\ 4 University of Naples Federico II, Department of Humanities, Naples 80133, Italy; benedetta.muzii@unina.it \\ * Correspondence: cristiano.scandurra@unina.it; Tel.: +39-334-152-3239
}

Received: 7 January 2020; Accepted: 6 February 2020; Published: 8 February 2020

Featured Application: This study presents the Italian version of the Level of Exposure-Dental Experiences Questionnaire (LOE-DEQ), a self-report checklist on dental and non-dental distressing events, allowing Italian researchers and dentists to benefit from the use of the LOE-DEQ in their research and clinical practice.

Abstract: The aim of this monocentric cross-sectional study was to evaluate the psychometric characteristics of the Italian version of the Level of Exposure-Dental Experiences Questionnaire (LOE-DEQ) in an Italian sample of 253 dental patients ranging from 18-80 years of age. The LOE-DEQ assesses 16 potential dental distressing experiences and 7 general traumatic life events through 4 subscales: (1) dentists' behaviour and patients' emotions (DBPE); (2) distressing dental procedures (DDP); (3) other distressing dental events (ODDE); and (4) general traumatic events (GTE). Confirmatory factor analysis showed that the original 4-factor model had adequate fit to the data obtained from the Italian sample. Criterion validity was partially confirmed as only DBPE and DDP positively correlated with dental anxiety. Similarly, convergent validity was also partially confirmed as DBPE, DDP, and ODDE correlated with negative beliefs towards the dentist and the dental treatment. Discriminant validity was fully confirmed, as all correlations were below 0.60 . Finally, DDP was the factor most associated with high dental anxiety. This study offers evidence of the reliability and validity of the LOE-DEQ in the Italian context, providing Italian researchers and dentists with a tool to assess dental and general distressing experiences in dental patients.

Keywords: dental anxiety; trauma; distress; validation; Level of Exposure-Dental Experiences Questionnaire

\section{Introduction}

Dental anxiety can be defined as an aversive emotional state of worry or apprehension in anticipation of dental treatment [1] and can have serious repercussions on oral health, representing a significant barrier to the access to dental care [2,3]. In terms of high dental anxiety, research has shown a prevalence ranging from $10 \%$ to $20 \%$ of adults in Western societies $[4,5]$. 
Within a multifactorial etiology model, Willumsen et al. [6] reported that previous negative dental experiences (e.g., painful experiences in the dental field) play a fundamental role in the development of dental anxiety. To this end, de Jongh et al. [7] found that individuals with high dental anxiety were more likely to report higher rates of traumatic dental experiences than those with lower dental anxiety (73\% vs. $21 \%)$.

Given the central role of traumatic experiences in the development of dental anxiety, Oosterink et al. [8] developed the Level of Exposure-Dental Experiences Questionnaire (LOE-DEQ), a self-report checklist inquiring into 23 potentially traumatic events, both inside and outside the dental setting. Specifically, the LOE-DEQ assesses 16 potentially traumatic dental experiences and 7 general traumatic life events (e.g., sexual abuse) through 4 subscales: (1) dentists' behaviour and patients' emotions (DBPE; i.e., distressing events relating to the dentist as a person and distressing emotional responses); (2) distressing dental procedures (DDP; i.e., distressing dental treatment experiences); (3) other distressing dental events (ODDE; i.e., negative dental experiences witnessed or heard about, but not lived in the first person); and (4) general traumatic events (GTE; i.e., distressing, non-dental experiences). This measure was tested on patients with high dental anxiety, general dental patients, psychiatric outpatients, students, and oral surgery patients and showed a sufficient internal consistency and a satisfactory test-retest reliability, as well as an adequate discriminant, predictive, and concurrent validity. Therefore, the LOE-DEQ can be considered a valid tool for assessing previous exposure to distressing dental events and, thus, to predicting potential vulnerability factors in the development of dental anxiety.

In Italy, where the current study was conducted, no comprehensive measures of the exposure to distressing dental events exist, leaving Italian researchers and dentists in need of a measure evaluating this important vulnerability factor among Italian dental patients. To achieve this objective, the current work was aimed to validate the LOE-DEQ with a sample of Italian patients who had attended a public dental surgery unit of a southern Italian university. To evaluate the fit of the model, we hypothesized that the 4 subscales would have good fit indices in the Italian sample (Hypothesis 1 ). To evaluate the criterion validity of the LOE-DEQ, we hypothesized that each subscale would correlate positively with dental anxiety (Hypothesis 2). To assess the convergent validity, we hypothesized that each subscale would correlate positively with a negative view about the dentist and dental treatment (Hypothesis 3). To evaluate the discriminant validity, we followed Kazdin's recommendations [9] on the conceptual distinction between constructs, hypothesizing that all the correlations described in the previous hypotheses would be below 0.60 (Hypothesis 4). Finally, being interested in assessing which LOE-DEQ dimensions were more closely associated with high dental anxiety, we hypothesized that distressing dental treatment experiences (DDP) would have the strongest impact on high dental anxiety (Hypothesis 5).

\section{Materials and Methods}

\subsection{Procedures and Participants}

The data analyzed in the current cross-sectional study are part of a larger data collection project entitled "A psychological model of dental anxiety," an Italian study aimed at analyzing the role of different psychological dimensions (e.g., personality traits, attachment, and defenses) in the development of dental anxiety. To collect data, patients having access to the Dental Surgery Unit of the University of Naples Federico II in order to undergo dental treatment in a day hospital, ordinary hospitalization, or pre-recovery were asked to participate in the study during their first appointment, between September 2018 and October 2019. The eligibility criteria were: (1) age between 18 and 80 years; (2) subjects able to understand and sign the informed consent; (3) subjects able to complete the questionnaire independently; and (4) subjects attending the oral surgery department to undergo dental surgery in a day hospital, ordinary hospitalization or pre-recovery. Informed written consent was obtained, and the participation was entirely voluntary and with no obligation. 
A total of 287 participants took part in the survey. Among them, 253 participants completed the LOE-DEQ, thus constituting the current final sample. Sociodemographic characteristics of the final sample are presented in Table 1.

Table 1. Descriptive statistics of participants.

\begin{tabular}{cc}
\hline Variable & $\begin{array}{c}\text { Patients }(\boldsymbol{N}=\mathbf{2 5 3}) \\
\boldsymbol{n}(\mathbf{\%}) \text { or } \mathbf{M} \pm \mathbf{S D}\end{array}$ \\
\hline Age (years) & $49.1 \pm 16.4$ \\
Mean & $18-80$ \\
Range & $124(49)$ \\
Gender & $129(51)$ \\
Male & \\
Female & $213(86.2)$ \\
Education & $34(13.8)$ \\
$\leq$ High school & \\
$\geq$ College & $239(94.5)$ \\
Recovery & $4(1.6)$ \\
Day hospital & $10(4)$ \\
Ordinary & \\
Pre-recovery & $14.3 \pm 5.8$ \\
\hline Mean & $5-25$ \\
Range & $71(28.7)$ \\
\hline Modified & Dental Anxiety Scale
\end{tabular}

Note: $\mathrm{SD}=$ Standard Deviation; ${ }^{*}$ Cut-off indicative of a high level of dental anxiety.

The study was conducted in accordance with the EU General Data Protection Regulation, approved by the "Ethical Committee of the University of Naples Federico II" (project identification code: 1043/18; date of approval: 17th July 2018), and designed in respect of the principles of the Declaration of Helsinki on Ethical Principles for Medical Research Involving Human Subjects.

\subsection{Measures}

The patients completed three questionnaires. First, participants filled out the LOE-DEQ, which requires to indicate whether or not (with a yes/no response) they had experienced specific traumatic events, allowing us to obtain an overall frequency score ranging from 0-8 for DBPE, $0-5$ for DDP, 0-3 for ODDE and 0-7 for GTE.

Secondly, participants answered the Modified Dental Anxiety Scale (MDAS) [10]. The MDAS is a 5-item scale measuring dental anxiety and responses are scored from 1 to 5 , producing a total score ranging from 5 (not anxious) to 25 (extremely anxious). The cut-off point of 19 is considered indicative of a high level of dental anxiety. The alpha coefficient for the current sample was 0.93 .

Thirdly, participants answered the revised version of the Dental Beliefs Survey (DBS-R) [11]. The DBS-R is a 28-item scale assessing the patient's perception of the dentist and the dental treatment through 3 subscales: (1) Professionalism (P), which assesses technical competence (i.e., whether or not dentists seem to make therapeutic decisions based on the best interests of the patient rather than their own best interests); (2) Communication (C), which assesses the ease of communication between the patient and dentist, and the attitude of the dentist towards the patient; and (3) Lack of Control (LC), which assesses feelings of control or helplessness and the patients' opinions about the possibility or not of being able to take a break during the treatment. Responses are scored from 1 (never) to 5 (nearly always), and higher scores on each subscale indicate greater negative beliefs. The alpha coefficients for the current sample were $0.86,0.92$, and 0.91 , for the three subscales, respectively. 


\subsection{Level of Exposure-Dental Experiences Questionnaire (LOE-DEQ) Translation}

The LOE-DEQ was translated into Italian following the back-translation method [12] according to which five phases were implemented, as follows: (1) each item of the LOE-DEQ was independently translated from English to Italian by three experts in the fields of dentistry and psychology; (2) the 3 Italian versions of the LOE-DEQ were compared and an agreement on a final version was reached (the first, second, and sixth authors); (3) the new Italian version of the LOE-DEQ was translated from Italian to English by a native English speaker with an excellent proficiency in the Italian language; (4) the new English version of the LOE-DEQ was compared with the original by the fourth and seventh author of the current work, who found an agreement on the final version; and (5) three independent researchers participated in a short online survey to evaluate the contents and comprehensibility of each item. The instructions were "How clear are the contents of the following items?" On a five-point Likert scale (from "not at all clear" to "completely clear") the average of all items was 4.77. The Italian version of the LOE-DEQ is reported in Appendix A.

\subsection{Statistical Analyses}

The preliminary analysis mainly concerned the handling of missing data (1.4\% of the total), which were treated through the multiple imputation by chained equations (MICE) method. We conducted this procedure under the hypothesis of missing at random, as variables within scales and between scales were considered to be correlated and missing data were not related to the total scores of the four scales. Specifically, the data were imputed through the mice R package [13] which allows the imputation of all types of variables. A total of 5 imputed datasets were created as the percentage of missing data was low. All the statistical analyses were run on the imputed datasets and the results presented were the pooled estimates from these datasets.

To evaluate the model fit of the 4-factor model structure behind the LOE-DEQ scale, all measurement models were specified as reflective [14] and confirmatory factor analysis (CFA) was performed using the lavaan R package. Since variables were dichotomous, the robust weighted least square (WLSMV) estimator was used. To apply the analysis on the multiply imputed data and then pool the results, we used the runMi function implemented in the semTools R package. The model fit was assessed by analyzing the estimated loadings and through the following indices: chi square/degrees of freedom ( $\mathrm{x} 2 / \mathrm{df})$, root mean square error of approximation (RMSEA), standardized root mean square residual (SRMR), comparative fit index (CFI), and Tucker-Lewis index (TLI). Values of $\chi 2 / \mathrm{df}<2$, RMSEA and SRMR $<0.08$, and TLI and CFI $>0.95$ are indicative of a good fit with the data $[15,16]$.

To evaluate the internal consistency reliability of each scale we computed the Cronbach's alpha, while the criterion, convergent, and discriminant validity of the LOE-DEQ were evaluated by computing the Pearson's correlation coefficient between the LOE-DEQ subscale scores, MDAS total score, and DBS-R subscale scores. The associations between the LOE-DEQ subscales and high dental anxiety were analyzed by a binary logistic regression, considering the 4 subscale scores as explanatory variables and high dental anxiety as a dichotomous dependent variable $(\geq 19$ vs. $<19)$. The crude odds ratio (OR) with $95 \%$ confidence intervals $(95 \% \mathrm{CI}$ ) from a univariate analysis and the adjusted odds ratio (AOR) with $95 \% \mathrm{CI}$ from a multivariate analysis were calculated, indicating the variation as the odds of high-level dental anxiety with respect to low-level dental anxiety, for a unit increase in each subscale score value. Finally, estimates for both the Cronbach's alpha and Pearson's correlation coefficient obtained for each imputed dataset were pooled using the mice $\mathrm{R}$ package.

\section{Results}

A high percentage (28.7\%) of the sample was above the MDAS threshold ( $\geq 19)$, the cut-off to detect the presence of high dental anxiety. A logistic regression was performed to ascertain the effects of age and gender on the likelihood that participants would have high dental anxiety. Only gender 
proved to be significant, with women being 3.62 times more likely to exhibit high dental anxiety than men $(\mathrm{B}=1.3, \mathrm{SE}=0.3, \mathrm{AOR}=3.6,95 \% \mathrm{CI}=1.9$ to $6.6, p<0.001)$.

No participants declared having experienced sexual assault (item LOE-DEQ 22). For the lack of variability, the item was removed from the model. The original 4 -factor model proposed by Oosterink et al. [8] fitted the data obtained from the Italian sample, confirming our first hypothesis. Specifically, the following indices were found: $\chi 2 / \mathrm{df}=1.41 ; \mathrm{CFI}=0.95 ; \mathrm{RMSEA}=0.04(\mathrm{CI}=0.03$ to $0.05)$; SRMR $=0.001 ; \mathrm{TLI}=0.94$. The internal consistency reliability assessed through the Cronbach's alpha, except for the GTE subscale ( $\alpha=0.49$ ), was adequate, ranging from 0.66 to 0.75 . The full model statistics (i.e., factor loadings, standardized factor loadings, Cronbach's alphas, means, and standard deviations) are reported in Table 2.

Table 2. Confirmatory factor analysis of Level of Exposure-Dental Experiences Questionnaire.

\begin{tabular}{|c|c|c|c|c|}
\hline Scale & Alpha & Range & Total Score: M (SD) & \\
\hline LOE-DEQ-DBPE & 0.75 & $0-8$ & $1.19(1.70)$ & \\
\hline Item & & & Factor Loading (SE) & Std. Loading \\
\hline LOE-DEQ 1 & & & 1.00 & 0.65 \\
\hline LOE-DEQ 2 & & & $1.18(0.17)$ & 0.76 \\
\hline LOE-DEQ 3 & & & $0.95(0.17)$ & 0.63 \\
\hline LOE-DEQ 4 & & & $1.04(0.17)$ & 0.67 \\
\hline LOE-DEQ 5 & & & $0.85(0.15)$ & 0.57 \\
\hline LOE-DEQ 6 & & & $1.36(0.19)$ & 0.88 \\
\hline LOE-DEQ 7 & & & $1.34(0.18)$ & 0.86 \\
\hline LOE-DEQ 8 & & & $0.90(0.18)$ & 0.57 \\
\hline LOE-DEQ-DDP & 0.66 & $0-5$ & $0.67(1.10)$ & \\
\hline Item & & & Factor Loading (SE) & Std. Loading \\
\hline LOE-DEQ 9 & & & 1.00 & 0.75 \\
\hline LOE-DEQ 10 & & & $0.87(0.14)$ & 0.67 \\
\hline LOE-DEQ 11 & & & $1.16(0.14)$ & 0.87 \\
\hline LOE-DEQ 12 & & & $1.00(0.15)$ & 0.76 \\
\hline LOE-DEQ 13 & & & $0.94(0.14)$ & 0.70 \\
\hline LOE-DEQ-ODDE & 0.66 & $0-3$ & $0.49(.75)$ & \\
\hline Item & & & Factor Loading (SE) & Std. Loading \\
\hline LOE-DEQ 14 & & & 1.00 & 0.81 \\
\hline LOE-DEQ 15 & & & $0.75(0.18)$ & 0.58 \\
\hline LOE-DEQ 16 & & & $0.68(0.19)$ & 0.56 \\
\hline LOE-DEQ-GTE & 0.49 & $0-7$ & $0.85(1.10)$ & \\
\hline Item & & & Factor Loading (SE) & Std. Loading \\
\hline LOE-DEQ 17 & & & 1.00 & 0.56 \\
\hline LOE-DEQ 18 & & & $0.69(0.24)$ & 0.38 \\
\hline LOE-DEQ 19 & & & $1.23(0.35)$ & 0.67 \\
\hline LOE-DEQ 20 & & & $1.38(0.43)$ & 0.76 \\
\hline LOE-DEQ 21 & & & $1.22(0.39)$ & 0.67 \\
\hline LOE-DEQ 22 & & & I & / \\
\hline LOE-DEQ 23 & & & $1.82(0.56)$ & 1.00 \\
\hline
\end{tabular}

Note: LOE-DEQ-DBPE = Dentists' behaviour and patients' emotions; LOE-DEQ-DDP = Distressing dental procedures; LOE-DEQ-ODDE = Other distressing dental events; LOE-DEQ-GTE = General traumatic events; $\mathrm{M}=$ Mean; $\mathrm{SD}=$ Standard Deviation; $\mathrm{SE}=$ Standard Error; Std. Loading = Standardized factor loading.

Correlational analyses for hypotheses 2 and 3 are reported in Table 3. Regarding the criterion validity of the LOE-DEQ, the subscales DBPE and DDP, as well as the total score, correlated positively with dental anxiety, indicating that higher rates of distressing dental events were associated with higher levels of dental anxiety. On the contrary, neither the ODDE nor GTE subscales correlated with dental anxiety. Thus, the criterion validity was partially confirmed. The effect sizes ranged from 0.18 to 0.26 . 
Table 3. Correlations between LOE-DEQ, Modified Dental Anxiety Scale, and Dental Beliefs Survey

\begin{tabular}{|c|c|c|c|c|c|c|c|c|c|c|}
\hline Scales & 1 & 2 & 3 & 4 & 5 & 6 & 7 & 8 & 9 & 10 \\
\hline 1. LOE-DEQ (tot) & 1.00 & & & & & & & & & \\
\hline 2. LOE-DEQ-DBPE & $0.83^{* * *}$ & 1.00 & & & & & & & & \\
\hline 3. LOE-DEQ-DDP & $0.73 * * *$ & $0.50 * * *$ & 1.00 & & & & & & & \\
\hline 4. LOE-DEQ-ODDE & $0.49^{* * *}$ & $0.22 * * *$ & 0.12 & 1.00 & & & & & & \\
\hline 5. LOE-DEQ-GTE & $0.57^{* * *}$ & $0.18 * *$ & $0.25^{* * *}$ & $0.29^{* * *}$ & 1.00 & & & & & \\
\hline 6. MDAS & $0.23 * * *$ & $0.26^{* * *}$ & $0.18^{* *}$ & 0.10 & 0.01 & 1.00 & & & & \\
\hline 7. DBS-R (tot) & $0.41^{* * *}$ & $0.41 * * *$ & $0.33^{* * *}$ & $0.20 * *$ & 0.08 & $0.27^{* * *}$ & 1.00 & & & \\
\hline 8. DBS-R-P & $0.42 * * *$ & $0.40^{* * *}$ & $0.31 * * *$ & $0.22^{* * *}$ & 0.14 * & $0.23 * * *$ & $0.92 * * *$ & 1.00 & & \\
\hline 9. DBS-R-C & $0.33^{* * *}$ & $0.34 * * *$ & $0.28^{* * *}$ & $0.15 *$ & 0.03 & $0.21 * * *$ & $0.93 * * *$ & $0.76^{* * *}$ & 1.00 & \\
\hline 10. DBS-R-LC & $0.37^{* * *}$ & $0.39 * * *$ & $0.30^{* * *}$ & $0.17^{* *}$ & 0.03 & $0.31^{* * *}$ & $0.91 * * *$ & $0.71 * * *$ & $0.83^{* * *}$ & 1.00 \\
\hline
\end{tabular}

Note: LOE-DEQ-DBPE = Dentists' behaviour and patients' emotions; LOE-DEQ-DDP = Distressing dental procedures; LOE-DEQ-ODDE = Other distressing dental events; LOE-DEQ-GTE = General traumatic events; MDAS $=$ Modified Dental Anxiety Scale; DBS-R-P = Professionalism; DBS-R-C = Communication; DBS-R-LC = Lack of Control; ${ }^{*} p<0.05 ; * * p<0.01 ; * * * p<0.001$.

Regarding the convergent validity of the LOE-DEQ, the subscales DBPE, DDP, and ODDE, as well as the total score, correlated positively with each of the DBS-R subscales, indicating that higher rates of distressing dental events were associated with more negative beliefs about the dentist and the dental treatment. On the contrary, among the DBS-R subscales, GTE correlated positively only with Professionalism. Thus, also the convergent validity was partially confirmed. The effect sizes ranged from 0.14 to 0.42 .

Regarding the discriminant validity of the LOE-DEQ, the fourth hypothesis was confirmed, as all correlations related to the hypotheses 2 and 3 were below 0.60 .

Finally, regarding the associations between the LOE-DEQ dimensions and high dental anxiety (Table 4), the results indicated that, when considering one variable at a time, only DBPE and DDP were significantly associated with high dental anxiety. On the contrary, when considering all the variables together, or rather the estimated effect and the effect of each variable maintaining all other variables constant, only DDP proved to be associated with high dental anxiety; specifically, the likelihood of having high dental anxiety significantly increased by $43 \%$ for each unitary increase of DDP, confirming our hypothesis.

Table 4. Logistic regression of LOE-DEQ on high dental anxiety.

\begin{tabular}{ccccc}
\hline & \multicolumn{2}{c}{ Univariate Analysis } & \multicolumn{2}{c}{ Multivariate Analysis } \\
\hline & OR (95\% CI) & $p$ Value & AOR (95\% CI) & $p$ Value \\
\hline LOE-DEQ-DBPE & $1.29(1.1,1.5)$ & 0.002 & $1.18(0.9,1.4)$ & 0.085 \\
LOE-DEQ-DDP & $1.53(1.2,1.9)$ & 0.001 & $1.43(1.1,1.9)$ & 0.015 \\
LOE-DEQ-ODDE & $1.17(0.8,1.7)$ & 0.392 & $1.17(0.7,1.7)$ & 0.607 \\
LOE-DEQ-GTE & $0.94(0.7,1.2)$ & 0.658 & $0.77(0.6,1.1)$ & 0.114 \\
\hline
\end{tabular}

LOE-DEQ-DBPE = Dentists' behaviour and patients' emotions; LOE-DEQ-DDP = Distressing dental procedures; LOE-DEQ-ODDE = Other distressing dental events; LOE-DEQ-GTE = General traumatic events; OR = Odds Ratio; $\mathrm{CI}=$ Confidence Intervals; $\mathrm{AOR}=$ Adjusted Odds Ratio.

\section{Discussion}

The current study aimed to evaluate the psychometric characteristics of the LOE-DEQ in an Italian sample of dental patients. The results obtained through the CFA showed an appropriate fit to the data, confirming the original 4-factor structure. Furthermore, our analysis demonstrated that the LOE-DEQ has a good criterion, convergent, and discriminant validity in the Italian sample. To the best of our knowledge, this is the first measure of the impact of distressing dental events available for use in the Italian context, providing Italian researchers and dentists with a valuable instrument to assess this dimension in the Italian population.

The participants of the current study showed a rate of dental anxiety significantly higher than that detected in the study validating the MDAS in the Italian context, where $2.4 \%$ of dental patients and $13.9 \%$ 
of online respondents matched the criteria to be categorized as highly anxious individuals [17]. Similarly, our sample also showed higher levels of dental anxiety than those detected in the representative UK study upon which MIDAS was created ( $28.7 \%$ vs. $11.6 \%$ ). This finding may be explained through the sample size which, although acceptable if compared to that recruited for the Italian validation of the MDAS [17] was not so large and was recruited from only one clinic. Future studies should expand their samples and recruit participants from diverse social realities. Furthermore, the finding related to gender differences in high dental anxiety is in line with previous studies, confirming that women are more anxious than men [18].

Regarding the criterion validity, we found significant associations between distressing experiences related to both treatment and the dentist as a person with dental anxiety. This is in line with previous studies highlighting the pivotal role of distressing dental experiences in the development of dental anxiety [7]. On the contrary, neither the negative dental experiences lived in the third person nor general traumatic experiences were associated with dental anxiety, disconfirming the results obtained by Oosterink et al. [8]. Our findings are more similar to those obtained by Humphris and King [18], who found that distressing dental experiences had a greater impact on dental anxiety than distressing experiences outside the dental setting. However, among general traumatic experiences, Humphris and King [18] found that sexual assault was the only general distressing experience outside the dental setting which significantly affected high dental anxiety. In our sample, no participants declared that they had experienced sexual assault. Thus, it is very likely that the lack of any associations between general traumatic experiences and dental anxiety may be related to this consideration. Future studies should expand the sample, including participants who have experienced sexual assault in the past.

On the other hand, our results confirmed both the convergent and discriminant validity of the Italian version of the LOE-DEQ. Indeed, except for the subscale GTE, which correlated only with Professionalism, all the other subscales correlated positively with all the subscales of the DBS-R. Furthermore, all the correlations calculated were below 0.60 . These findings demonstrate that the LOE-DEQ is able to measure meaningful and independent constructs. The only exception regards the GTE subscale, which did not show a high internal consistency reliability. However, even in the samples recruited by Oosterink et al. [8] GTE was the subscale with the lowest internal consistency reliability compared to the other subscales, ranging from 0.33 to 0.62 , depending on the sample on which it was calculated. This means that Italian researchers and dentists should use this subscale with caution, associating it with the LOE-DEQ other scales measuring general distressing and traumatic events.

Regarding the associations between the LOE-DEQ dimensions and high dental anxiety, the results confirmed the hypothesis that distressing dental experiences lived within the dental setting were experiences more predictive of high dental anxiety than both distressing experiences lived outside the dental setting and the emotions associated with the dentist as a person. This finding is in line with a previous study highlighting that dentally anxious patients were more likely to report traumatic dental events than patients with lower levels of dental anxiety [7]. However, more recent studies have reported evidence that multiple pathways in the development of dental anxiety exist, but not all individuals with high levels of dental anxiety report traumatic dental experiences [19]. For this reason, future Italian studies should assess in detail the role of both traumatic and non-traumatic negative events in the development of dental anxiety.

The results should be read in the light of important limitations. First, the cross-sectional nature of the study did not allow us to evaluate the convergent validity of the LOE-DEQ completely. Future studies should consider assessing the convergent validity at different measurement times (e.g., before and after specific dental procedures). Secondly, even if acceptable, the sample size was not very large and the participants were recruited from only one social reality, preventing the possibility of any geographical generalizability. Thirdly, no participants in the current study had experienced sexual assault, a factor which had proved to be particularly meaningful in previous studies [18]. Future studies should recruit bigger and more diverse samples of patients to verify whether this association is consistent also in Italian dental patients. 


\section{Conclusions}

Notwithstanding the limitations, this study allows Italian researchers and dentists to benefit from the use of the LOE-DEQ in their practice, also informing clinical psychological interventions [2023]. Indeed, Italian researchers will be able to expand scientific knowledge on distressing dental and non-dental events in their associations with dental anxiety or other debilitating symptoms (e.g., avoidance and anger), while Italian dentists will be able to use the LOE-DEQ within clinical settings to discuss with their clients their unique past experiences which may affect the effectiveness of dental interventions.

Author Contributions: Conceptualization, C.S., R.G., G.S. (Gilberto Sammartino) and N.M.M.; methodology, C.S., R.G. and P.D.; formal analysis, P.D.; investigation, C.S., R.G., V.B. and B.M.; resources, G.S. (Gianrico Spagnuolo) and G.M.; data curation, C.S., R.G., P.D. and B.M.; writing-original draft preparation, C.S. and R.G.; writing-review and editing, V.B., B.M., G.S. (Gilberto Sammartino), G.M. and G.S. (Gianrico Spagnuolo) and N.M.M.; supervision, G.S. (Gilberto Sammartino) and N.M.M.; project administration, C.S., R.G. and B.M.; C.S. and R.G. contributed equally. All authors have read and agreed to the published version of the manuscript.

Funding: This research received no external funding.

Conflicts of Interest: The authors declare no conflict of interest.

\section{Appendix A}

Italian Version of the LOE-DEQ.

Per favore, risponda alle domande seguenti mettendo una " $X$ " su SI oppure NO, sulla base della sua esperienza

\begin{tabular}{lcc}
\hline È mai stato/a esposto/a ad un evento durante il quale & & \\
\hline 1. Un dentista l'ha criticata? & $\mathrm{Si}$ & No \\
2. Un dentista sembra non averla capita? & $\mathrm{Si}$ & No \\
3. Un dentista non le ha fornito informazioni su trattamenti invasivi? & $\mathrm{Si}$ & No \\
4. Ha avuto un dentista scortese o sgarbato? & $\mathrm{Si}$ & No \\
5. Ha provato molta vergogna durante un trattamento dentale? & $\mathrm{Si}$ & No \\
6. Si è sentito/a estremamente indifeso/a durante un trattamento dentale? & $\mathrm{Si}$ & No \\
7. Si è sentito/a estremamente male durante un trattamento dentale? & $\mathrm{Si}$ & No \\
8. Si è sentito/a quasi soffocare durante un trattamento? & $\mathrm{Si}$ & No \\
9. Si è sottoposto/a ad una devitalizzazione che le ha causato un dolore estremo o & $\mathrm{Si}$ & No \\
qualche altro grave disagio? & & \\
10. Le è stato forato un dente che le ha causato un dolore estremo o qualche altro & $\mathrm{Si}$ & No \\
grave disagio? & $\mathrm{Si}$ & No \\
11. Ha sofferto di un dolore estremo dopo un trattamento dentale? & $\mathrm{Si}$ & No \\
12. Durante un trattamento dentale le è stata fatta un'iniezione che le ha causato un \\
dolore estremo o qualche altro grave disagio? & & \\
13. Le è stato estratto un dente che le ha causato un dolore estremo o qualche altro & $\mathrm{Si}$ & No \\
grave disagio? & & \\
14. Ė venuto/a a conoscenza di storie terrificanti o orribili su delle & $\mathrm{Si}$ & No \\
esperienze dentistiche? & & \\
15. È venuto/a a conoscenza di informazioni mediatiche riguardanti l'odontoiatria che \\
le hanno causato gravi disagi? & $\mathrm{Si}$ & No \\
16. Ha assistito a un trattamento di un paziente estremamente ansioso? & $\mathrm{Si}$ & No \\
17. Ė rimasto/a gravemente ferito/a in un incidente? & $\mathrm{Si}$ & No \\
18. È stato/a vittima di un disastro naturale o di una guerra? & $\mathrm{Si}$ & No \\
19. Ha visto qualcuno ferito gravemente o ucciso? & $\mathrm{Si}$ & No \\
20. Ha assistito a una tragica morte o malattia? & $\mathrm{Si}$ & No \\
21. Ha vissuto un trattamento medico terrificante? & $\mathrm{Si}$ & No \\
22. È stato/a vittima di violenza sessuale? & $\mathrm{Si}$ & No \\
23. È stato/a vittima di un crimine violento? & $\mathrm{Si}$ & No \\
\hline
\end{tabular}




\section{References}

1. Armfield, J.M. Towards a better understanding of dental anxiety and fear: Cognitions vs. experiences. Eur. J. Oral Sci. 2010, 118, 259-264. [CrossRef] [PubMed]

2. Halvari, A.E.M.; Halvari, H.; Deci, E.L. Dental anxiety, oral health-related quality of life, and general well-being: A self-determination theory perspective. Appl. Soc. Psychol. 2019, 49, 295-306. [CrossRef]

3. Hill, K.B.; Chadwick, B.; Freeman, R.; O'Sullivan, I.; Murray, J.J. Adult Dental Health Survey 2009: Relationships between dental attendance patterns, oral health behaviours and the current barriers to dental care. Br. Dent. J. 2013, 214, 25-32. [CrossRef] [PubMed]

4. Buunk-Werkhoven, Y.A.B.; Dijkstra, A.; Van Der Schans, C.P. Oral health-quality of life predictors depend on population. Appl. Res. Qual. Life 2009, 4, 283-293. [CrossRef]

5. Humphris, G.; Crawford, J.R.; Hill, K.; Gilbert, A.; Freeman, R. UK population norms for the Modified Dental Anxiety Scale with percentile calculator: Adult dental health survey 2009 results. BMC Oral Health 2013, 13, 29. [CrossRef] [PubMed]

6. Willumsen, T.; Haukebø, K.; Raadal, M. Aetiology of dental phobia. In Cognitive Behaviour Therapy for Dental Phobia and Anxiety; Öst, L.G., Skaret, E., Eds.; John Wiley \& Sons: Oxford, UK, 2013.

7. de Jongh, A.; Fransen, J.B.; Oosterink-Wubbe, F.M.D.; Aartman, I.H.A. Psychological trauma exposure and trauma symptoms among individuals with high and low levels of dental anxiety. Appl. Res. Qual. Life 2006, 114, 286-292. [CrossRef] [PubMed]

8. Oosterink, F.M.D.; de Jongh, A.; Hoogstraten, J.; Aartman, I.H.A. The Level of Exposure-Dental Experiences Questionnaire (LOE-DEQ): A measure of severity of exposure to distressing dental events. Appl. Res. Qual. Life 2008, 116, 353-361. [CrossRef]

9. Kazdin, A.E. Preparing and evaluating research reports. In Methodological Issues E Strategies in Clinical Research; Kazdin, A., Ed.; The American Psychological Association: Washington, DC, USA, 2003; pp. 837-858.

10. Humphris, G.M.; Morrison, T.; Lindsay, S.J. The Modified Dental Anxiety Scale: Validation and United Kingdom norms. Community Dent Health 1995, 12, 143-150.

11. Milgrom, P.; Weinstein, P.; Getz, T. Treating Fearful Dental Patients: A Patient Management Handbook, 2nd ed.; University of Washington: Seattle, WA, USA, 1995.

12. Behling, O.; Law, K.S. Translating Questionnaires and Other Research Instruments: Problems and Solutions; Sage Publications: Thousand Oaks, CA, USA, 2000.

13. Van Buuren, S.; Groothuis-Oudshoorn, K. Mice: Multivariate imputation by chained equations. J. Stat. Softw. 2011, 45, 1-67. [CrossRef]

14. Dolce, P.; Lauro, C.N. Comparing maximum likelihood and PLS estimates for structural equation modeling with formative blocks. Qual. Quant. 2015, 49, 891-902. [CrossRef]

15. Kline, R.B. Principles and Practice of Structural Equation Modeling; Guilford Publications: New York, NY, USA, 2015.

16. Scandurra, C.; Bochicchio, V.; Dolce, P.; Caravà, C.; Vitelli, R.; Testa, R.J.; Balsam, K.F. The Italian Validation of the Gender Minority Stress and Resilience Measure. Psychol. Sex. Orientat. Gend. Divers.. in press. [CrossRef]

17. Gremigni, P.; Mobilio, N.; Casu, G.; Catapano, S. Validation of the Modified Dental Anxiety Scale (MDAS) in an Italian sample and invariance across gender and mode of administration. Eur. J. Psychol. Assess 2014, 30, 140-149. [CrossRef]

18. Humphris, G.; King, K. The prevalence of dental anxiety across previous distressing experiences. J. Anxiety Disord. 2011, 25, 232-236. [CrossRef] [PubMed]

19. de Jongh, A.; van Eeden, A.; van Houtem, C.M.H.H.; van Wijk, A.J. Do traumatic events have more impact on the development of dental anxiety than negative, non-traumatic events? Eur. J. Oral Sci. 2017, 125, $202-207$. [CrossRef] [PubMed]

20. Amodeo, A.L.; Picariello, S.; Valerio, P.; Bochicchio, V.; Scandurra, C. Group psychodynamic counselling with final-year undergraduates in clinical psychology: A clinical methodology to reinforce academic identity and psychological well-being. Psychodyn. Pract. 2017, 23, 161-180. [CrossRef]

21. Scandurra, C.; Picariello, S.; Scafaro, D.; Bochicchio, V.; Valerio, P.; Amodeo, A.L. Group psychodynamic counselling as a clinical training device to enhance metacognitive skills and agency in future clinical psychologists. Eur. J. Psychol. 2018, 14, 444-463. [CrossRef] [PubMed] 
22. Sperandeo, R.; Moretto, E.; Iennaco, D.; Maldonato, N.M. Using complex networks to model, simulate and understand the dynamics of psychotherapeutic processes: An experimental study proposal. In 20189 th IEEE International Conference on Cognitive Infocommunications (CogInfoCom), Proceedings of the CogInfoCom 2018, Budapest, Hungary, 22-24 August 2018; IEEE Staff: Danvers, MA, USA, 2019; Volume 8639936, pp. 111-112.

23. Longobardi, T.; Sperandeo, R.; Albano, F.; Tedesco, Y.; Moretto, E.; Di Sarno, A.D.; Dell'Orco, S.; Maldonato, N.M. Co-regulation of the voice between patient and therapist in psychotherapy: Machine learning for enhancing the synchronization of the experience of anger emotion: An experimental study proposal. In 2018 9th IEEE International Conference on Cognitive Infocommunications (CogInfoCom), Proceedings of the CogInfoCom 2018, Budapest, Hungary, 22-24 August 2018; IEEE Staff: Danvers, MA, USA, 2019; Volume 8639875, pp. 113-116.

(C) 2020 by the authors. Licensee MDPI, Basel, Switzerland. This article is an open access article distributed under the terms and conditions of the Creative Commons Attribution (CC BY) license (http://creativecommons.org/licenses/by/4.0/). 